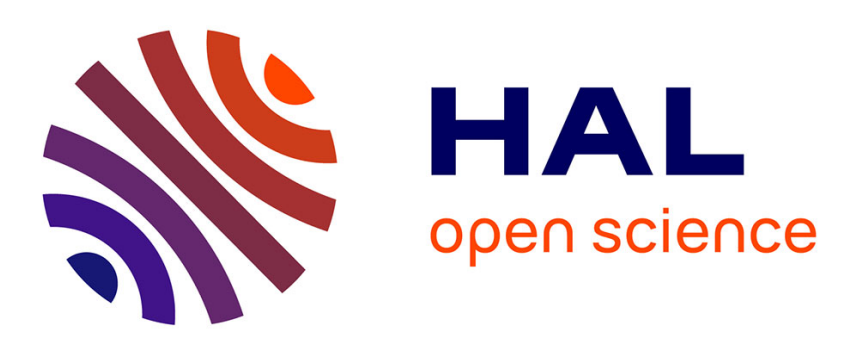

\title{
Induction machine bearing faults detection based on a multi-dimensional MUSIC algorithm and maximum likelihood estimation
}

El Houssin El Bouchikhi, Vincent V. Choqueuse, Mohamed Benbouzid

\section{- To cite this version:}

El Houssin El Bouchikhi, Vincent V. Choqueuse, Mohamed Benbouzid. Induction machine bearing faults detection based on a multi-dimensional MUSIC algorithm and maximum likelihood estimation. ISA Transactions, 2016, 63, pp.413-424. 10.1016/j.isatra.2016.03.007 . hal-01356692

\section{HAL Id: hal-01356692 \\ https://hal.science/hal-01356692}

Submitted on 1 Sep 2016

HAL is a multi-disciplinary open access archive for the deposit and dissemination of scientific research documents, whether they are published or not. The documents may come from teaching and research institutions in France or abroad, or from public or private research centers.
L'archive ouverte pluridisciplinaire HAL, est destinée au dépôt et à la diffusion de documents scientifiques de niveau recherche, publiés ou non, émanant des établissements d'enseignement et de recherche français ou étrangers, des laboratoires publics ou privés. 


\title{
Induction Machine Bearing Faults Detection based
}

\section{on a Multi-Dimensional MUSIC Algorithm and Maximum Likelihood Estimation}

\section{Elhoussin Elbouchikhi, Vincent Choqueuse, Mohamed Benbouzid}

\begin{abstract}
Condition monitoring of electric drives is of paramount importance since it contributes to enhance the system reliability and availability. Moreover, the knowledge about the fault mode behavior is extremely important in order to improve system protection and fault-tolerant control. Fault detection and diagnosis in squirrel cage induction machines based on Motor Current Signature Analysis (MCSA) has been widely investigated. Several high resolution spectral estimation techniques have been developed and used to detect induction machine abnormal operating conditions. This paper focuses on the application of MCSA for the detection of abnormal mechanical conditions that may lead to induction machines failure. In fact, this paper is devoted to the detection of single-point defects in bearings based on parametric spectral estimation. A multi-dimensional MUSIC (MD MUSIC) algorithm has been developed for bearing faults detection based on bearing faults characteristic frequencies. This method has been used to estimate the fundamental frequency and the fault related frequency. Then, an amplitude estimator of the fault characteristic frequencies has been proposed and fault indicator has been derived for fault severity measurement.

The proposed bearing faults detection approach is assessed using simulated stator currents data, issued from a coupled electromagnetic circuits approach for air-gap eccentricity emulating bearing faults. Then, experimental data are used for validation purposes.
\end{abstract}

\section{Keywords}

Induction machine, condition monitoring, bearing fault detection, signal processing, MD MUSIC, maximum likelihood estimation.

\section{NOMENCLATURE}

MD MUSIC = Multi-Dimensional Multiple Signal Classification;

ESPRIT = Estimation of Signal Parameters via Rotational Invariance Techniques;

MCSA $=$ Motor Current Signature Analysis; 


$\begin{array}{ll}\text { MLE } & =\text { Maximum Likelihood Estimation; } \\ f_{s} & =\text { Stator supply frequency; } \\ s & =\text { Per-unit slip; } \\ \text { DFT } & =\text { Discrete Fourier Transform; } \\ \text { MCMFT } & =\text { Maximum Covariance Frequency Tracking; } \\ \text { PSD } & =\text { Power Spectral Density; } \\ \text { SNR } & =\text { Signal to Noise Ratio; } \\ p & =\text { Pole pairs number. }\end{array}$

\section{INTRODUCTION}

In a wide variety of industrial applications, an increasing demand exists to improve reliability, availability, and safety of electrical systems. A sudden failure of a system may lead to cost-expensive downtime, damage to surrounding equipment or even danger to humans. Induction machine is omnipresent in these electrical systems. Although it is robust and reliable, the induction machine is subjected to several faults. Common failures that may occur can be roughly classified into stator winding short circuit, broken rotor bar, broken end-ring, rotor eccentricity, bearing faults, shaft misalignment, and load faults [1], [2]. In spite of the advances in failures detection, condition monitoring of induction machine is still a challenging task for engineers and researchers [3]-[5].

A common approach for condition monitoring is vibration monitoring [6]-[9]. However, this method is expensive since it requires costly additional transducers. A cost-effective alternative is stator currents analysis since currents measurement requires limited number of sensors and is already available for control and protection purposes [10]. In [11] the authors have performed a comparative study of vibration monitoring, stator current analysis and stray flux processing as media for induction machine mechanical unbalance fault detection. A literature survey showed the interest of the approach for mechanical and electrical faults detection [12]-[19]. A Hilbert-Park transform has been successfully used for mechanical fault diagnosis in induction machines in [20]. Most authors perform induction machine faults detection by monitoring the additional frequency components introduced by the fault. However, no precise stator currents model under fault is given. In various works, numerical machine models accounting for the fault are used without providing analytical stator current expressions [21]. 
Theoretical analysis has shown that faulty machine frequencies of interest are given by [5], [22]

$$
f_{k}=f_{s} \pm k f_{c}, k=0,1, \cdots, L
$$

where $f_{s}$ is the electrical supply frequency, $f_{c}$ corresponds to the fault characteristic frequency, and $2 \times L$ is the sidebands number. These frequencies are associated with air-gap eccentricity, bearing failures or broken rotor bars faults.

In steady-state condition, $f_{s}$ and $f_{c}$ are constants and techniques based on classical spectral estimators (Periodogram and its extensions) have been employed [4], [23]. In order to overcome the low frequency resolution of these techniques, high resolution techniques have been proposed such as MUSIC and Estimation of Signal Parameters via Rotational Invariance Techniques (ESPRIT) [24]-[29]. Moreover, in [30] the authors have proposed a parametric spectral estimation technique based on a maximum likelihood estimation that outperform the conventional techniques such as discrete Fourier transform (DFT) and MUSIC. In non stationary environment, more sophisticated techniques have been investigated such as timefrequency representations [31]-[35] and time-scale techniques [31], [36]. In addition to the aforementioned techniques, many faults detection procedures based on statistical analysis of the current signal have been proposed such as MCMFT [37] and adaptive statistical time-frequency methods [38] without presenting any fault detection criteria for an automatic fault diagnosis.

An overview of the existing works emphasizes the compromise between frequency accuracy, frequency resolution, statistical performance and computational cost of spectrum analysis techniques for fault detection in induction machine. Furthermore, it should be mentioned that the classical techniques do not take into account the particularity of electrical signals, such as specific frequency structure of the stator currents under faulty conditions.

In this paper, we propose a stator current signal analytical model that takes into account the particular structure of the fault sensitive frequencies given by (1). A stator current signal model is of great interest since it helps to develop suitable post-processing tools and detection strategies. Then, a high resolution signal processing technique, based on this model, is developed for fault related frequency estimation. Finally, a fault detection criterion is presented.

The major issue addressed in this paper is the development of a condition monitoring strategy that can make an accurate and reliable assessment of the presence of specific induction machine fault conditions, namely the bearing faults. Indeed, this paper focuses on the detection of single-point defects in a rolling 


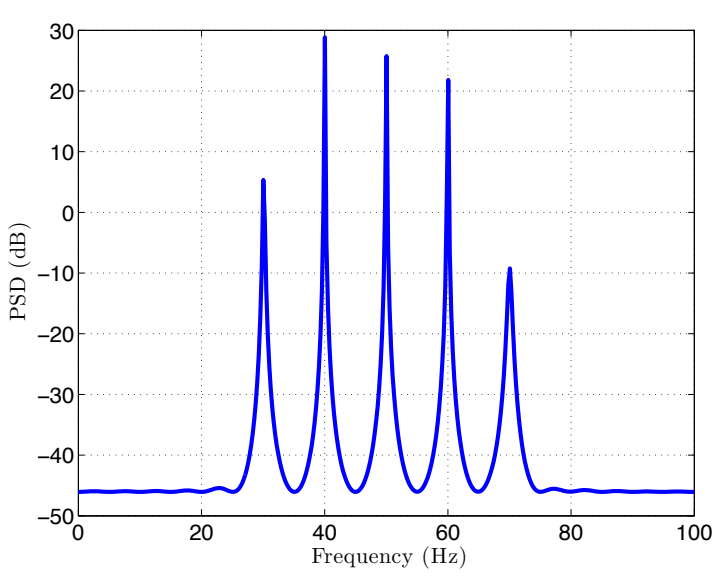

(a) Pseudo-spectrum estimate via MUSIC.

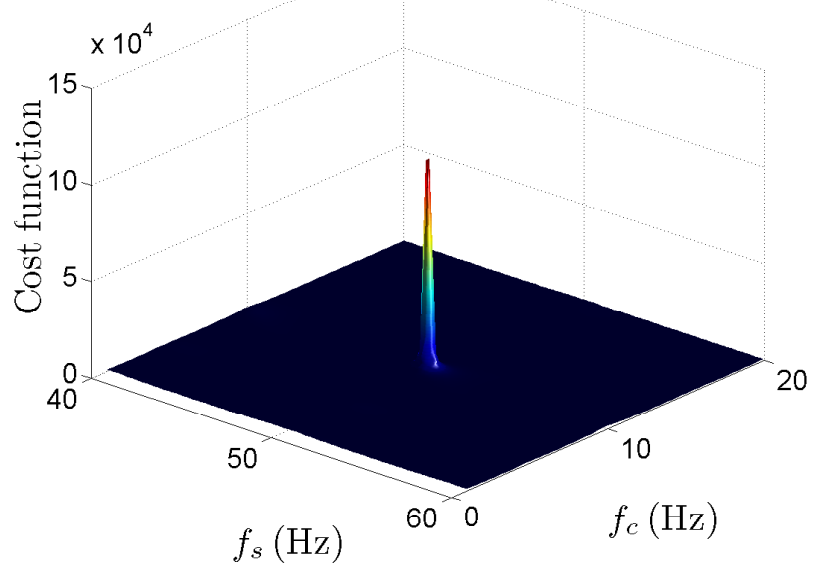

(b) MD MUSIC cost-function

Fig. 1. Cost-function for classical MUSIC and MD MUSIC (cost-function in the case of a synthetic signal with $f_{s}=50 \mathrm{~Hz}, f_{c}=10 \mathrm{~Hz}$, $L=2$ and $S N R=50 \mathrm{~dB}$ ).

element bearing. The proposed fault detection technique is based on three steps. First, the fundamental frequency, the fault characteristic frequency, and the number of sidebands (equivalent to model order selection [39], [40]) are estimated based on the MD MUSIC [41]. Then, the Maximum Likelihood Estimator (MLE), which is an optimal technique, is used to estimate the amplitude of the fault characteristic components. Finally, a fault detection criterion is computed using the estimated amplitudes [42]. This criterion allows to measure the fault severity and then could be used as input for an automatic fault detection procedure.

To illustrate the difference between the classical MUSIC algorithm [43], [44] and the proposed technique, Fig. 1 presents the MUSIC pseudo-spectrum and the MD MUSIC for a supply frequency of $f_{s}=50 \mathrm{~Hz}$, a fault characteristic frequency of $f_{c}=10 \mathrm{~Hz}$, and with $S N R=50 \mathrm{~dB}$. Figure 1a shows that the MUSIC pseudo-spectrum exhibits spectral peaks at $f_{s} \pm k f_{c}$. In contrast to the classical MUSIC, the proposed technique tracks the supply frequency and the characteristic frequency in a two-dimensional space. Figure $1 \mathrm{~b}$ shows that the multi-dimensional cost-function, which exhibits a single peak at $f_{s}=50 \mathrm{~Hz}$ and $f_{c}=10 \mathrm{~Hz}$. Compared to MUSIC, the proposed technique makes the estimation of $f_{s}$ and $f_{c}$ (and the subsequent processing) easier. Furthermore, as it exploits more information about the signal (the fault characteristic frequencies are introduced in the faulty induction machine stator current model), the proposed technique is expected to outperform the classical MUSIC algorithm. Finally, the proposed method allows to measure the fault related frequencies amplitude when the classical MUSIC does not give the true PSD (not the amplitude of the frequency bins). 
The major contributions of this paper are threefold:

- We propose a new model order and spectral estimation technique aiming at detecting the induction machine fault frequency signatures.

- We demonstrate the appropriateness of the approach on bearing fault detection in induction machine. In fact, it makes a potential failure identifiable and quantifiable.

- We prove the effectiveness of the technique on simulated and experimental data.

The remaining parts of the present work are organized as follows. Section 2 analyzes the effects of machine bearing faults on the stator current and presents a stator current signal analytical model based on the fault frequencies analytically reported in the literature. Section 3 describes the fault detection method based on advanced signal processing technique. Simulation results are presented in section 4 for bearing faults detection using air-gap eccentricity for emulation purposes. Then, experimental results reported in section 5 show the potentiality of the proposed methodology as a suited tool for bearing faults features extraction. Finally, section 6 concludes this work.

\section{Induction Machine Stator CurRent Model}

The following section presents the effects of air-gap eccentricity and bearing faults on the stator currents. Then, a stator current signal model for healthy and faulty machine with bearing faults is presented.

\section{A. Bearing Fault Types and Fault-Related Components}

Bearing failure is one of the foremost causes of breakdowns in rotating machinery, resulting in costly downtime [2]. Bearing faults can be categorized as either single-point defects or generalized roughness. Generalized roughness is the most common damage occurring to rolling bearings [45]. It produces unpredictable broadband effects in the machines vibration and current spectrum, but it seems to be feasible to detect them by means of the temporal vibration signal Root Mean Square analysis [46] or spectral Kurtosis energy of vibration or current signals [45]. In contrast, single-point defects are localized and can be classified according to the following affected elements: outer raceway defect, inner raceway defect, ball defect, cage fault. It may be similar to an incipient fault, with a spall created by a material defect, or a crater caused by bearing current.

This paper will particularly focus on bearing single-point defects. This type of fault produces a predictable characteristic fault frequencies in the vibration and currents waveforms [47]-[49]. In fact, local 


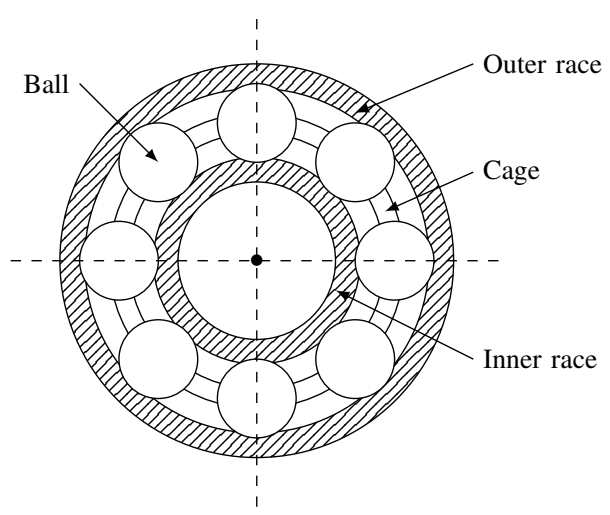

(a)

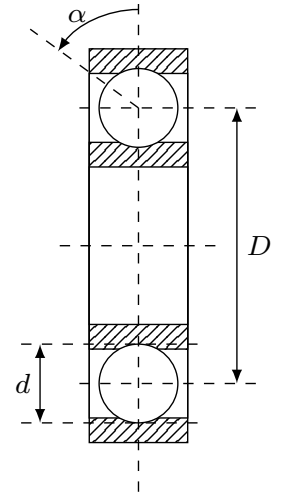

(b)

Fig. 2. Bearing structure with main dimensions.

or wear defects cause periodic impulses in vibration signals. Amplitude and frequency of such impulses are determined by shaft rotational speed, fault location, and bearing dimensions. The frequency of these impulses is given by (2)

$$
\left\{\begin{array}{l}
f_{c}=\frac{f_{r}}{2}\left(1-\frac{d}{D} \cos (\alpha)\right) \\
f_{b d}=\frac{D}{d} f_{r}\left(1-\frac{d^{2}}{D^{2}} \cos ^{2}(\alpha)\right) \\
f_{i d}=\frac{n_{r}}{2} f_{r}\left(1+\frac{d}{D} \cos (\alpha)\right) \\
f_{o d}=\frac{n_{r}}{2} f_{r}\left(1-\frac{d}{D} \cos (\alpha)\right)
\end{array}\right.
$$

where $f_{c}$ corresponds to fundamental cage frequency, $f_{b d}$ is ball defect frequency, $f_{i d}$ is inner race defect frequency, and $f_{o d}$ corresponds to outer race defect frequency. The parameter $f_{r}$ refers to shaft rotation frequency, $n_{r}$ is the number of rollers, $d$ is the roller diameter, $D$ is the pitch diameter of the bearing, and $\alpha$ is the contact angle (Fig. 2).

Since ball bearings support the rotor, any bearing defect will produce a radial motion between the rotor and the stator of the machine (air-gap eccentricity), which may lead to anomalies in the air-gap flux density. As the stator current for given phase is linked to flux density, the stator current is affected as well by the bearing defect [47], [49]. Hence, the eccentricity fault is used in order to emulate bearing faults on the numerical model of the induction machine. The bearing fault generates stator currents at frequencies given by (3).

$$
f_{\text {bear }}=\left|f_{s} \mp k f_{d}\right|
$$


where $k=1,2,3, \ldots$ and $f_{d}$ is one of the characteristic vibration frequencies given by (2).

The bearing faults and the air-gap eccentricity can be detected by monitoring the machine current spectral components produced by the magnetic field anomaly. This condition monitoring approach provides the advantage of not requiring any knowledge about the machine construction. The air-gap eccentricity and bearing faults sensitive frequencies are given by [4], [5]

$$
f_{\text {ecc }}=f_{s}\left[1 \pm m\left(\frac{1-s}{p}\right)\right] ; \quad m=1,2,3, \ldots \quad f_{\text {bear }}=\left|f_{s} \pm k f_{d}\right| ; \quad k=1,2,3, \ldots
$$

These faults characteristic frequencies can be expressed in the general form of (1). In the following, we propose a stator current signal model based on these fault characteristic frequencies.

\section{B. Signal Model}

In this paper, we consider a stator current signal model composed of $2 \times L+1$ complex-valued sinusoids. The proposed technique relies on the following assumption:

- $\mathcal{H}_{1}$ : The signal is assumed to be corrupted by an additive white noise. This assumption is not particularly restrictive since the noise can be whitened by appropriate choice of the sampling frequency or by filtering the signal by a linear whitening filter [43, Chapter 4, Parametric Methods for line spectra, Introduction]. Moreover, the central limit theorem, which states that, given certain conditions, the sum of a sufficiently large number of independent and identically random variables are approximately Gaussian distributed [50], [51].

$-\mathcal{H}_{2}$ : The phases of the complex sinusoids are independent and uniformly distributed on the interval $\left[-\pi, \pi\left[\right.\right.$ and $a_{k}>0$. We need to specify the sign of $a_{k}$ in order to avoid phase indetermination.

Using (1), the stator current can be expressed as:

$$
x[n]=\sum_{k=-L}^{L} a_{k} e^{j\left(\left(\omega_{s}+k \omega_{c}\right) n+\phi_{k}\right)}+b[n]
$$

where :

- The normalized pulsations $\omega_{s}$ and $\omega_{c}$ are defined as

$$
\omega_{s}=2 \pi f_{s} / F_{s} \quad \omega_{c}=2 \pi f_{c} / F_{s}
$$


where $F_{s}$ corresponds to the sampling rate;

- $a_{k}$ and $\phi_{k}$ denote the amplitude and the phase of the $k^{t h}$ sinusoid;

- $b[n] \sim \mathcal{N}_{c}\left(0, \sigma^{2}\right)$ is a complex circular white Gaussian noise i.e.:

$$
E[b(n)]=0 \quad E[b(n) b(n+\tau)]=0 \quad E\left[b(n) b^{*}(n+\tau)\right]=\sigma^{2} \delta(\tau)
$$

where $E\{\},.(.)^{*}$ and $\delta($.$) correspond to the statistical expectation, the complex conjugate and the$ Dirac delta, respectively.

One can notice that if $\omega_{s}=0 \mathrm{rad} . \mathrm{s}^{-1}$ then the signal corresponds to a periodic waveform. Furthermore, if $\omega_{c}=0$ rad.s $s^{-1}$ or $L=0$, the model reduces to a single complex sine wave embedded in Gaussian noise.

Let us construct the column vector, $\mathbf{x}[n]$, that contains $M$ consecutive samples of the observed signal i.e.

$$
\mathbf{x}[n]=[x[n], \cdots, x[n+M-1]]^{T}
$$

where $(.)^{T}$ denotes the matrix transpose. Using a matrix notation, (5) can be expressed as

$$
\mathbf{x}[n]=\mathbf{D}\left(f_{s}, n\right) \mathbf{A}\left(f_{c}, n\right) \mathbf{s}+\mathbf{b}[n]
$$

where:

- $\mathbf{b}[n]$ is a $M \times 1$ column vector containing the noise samples. This vector is defined as:

$$
\mathbf{b}[n]=[b[n], \cdots, b[n+M-1]]^{T}
$$

- $\mathbf{s}$ is a $(2 \times L+1) \times 1$ column vector containing the complex sine waves amplitudes. This vector is defined as

$$
\mathbf{s}=\left[a_{-L} e^{j \phi_{-L}}, \cdots, a_{L} e^{j \phi_{L}}\right]^{T}
$$

- $\mathbf{D}\left(f_{s}, n\right)$ is a $M \times M$ diagonal matrix whose elements are given by

$$
\mathbf{D}\left(f_{s}, n\right)=\operatorname{diag}\left(\left[e^{j \omega_{s} n}, e^{j \omega_{s}(n+1)}, \ldots, e^{j \omega_{s}(n+M-1)}\right]\right)
$$


- $\mathbf{A}\left(f_{c}, n\right)$ is a $M \times(2 L+1)$ Vandermonde matrix at time $n$ whose elements are given by

$$
\mathbf{A}\left(f_{c}, n\right)=\left[\mathbf{z}_{-L}(n) \ldots \mathbf{z}_{L}(n)\right]
$$

where the $m^{t h}$ entry of the column vector $\mathbf{z}_{k}(n) \in \mathbb{C}^{M}$ is defined as $\left[\mathbf{z}_{k}(n)\right]_{m}=e^{j \omega_{c} k(n+m-1)}$. Since $\mathbf{x}(n)$ has length $M$ and we have $N$ observations of $x(n)$, we can thus construct a set of $G=N-M+1$ different subvectors $\{\mathbf{x}(n)\}_{n=0}^{G-1}$.

- The Vandermonde matrix $\mathbf{D}\left(f_{s}, n\right) \mathbf{A}\left(f_{c}, n\right)$ at time $n$ has rank $2 L+1$, which implies that $M>2 L+1$ and $f_{c} \neq 0 \mathrm{~Hz}[43$, section 4.2.3].

Using the signal model in (9), we propose to estimate the model parameters, namely $\omega_{s}, \omega_{c}$ and the complex amplitudes $a_{l} e^{j \phi_{l}}$, from $x(n)(n=0, \cdots, N-1)$, where $N$ corresponds to the signal length.

\section{High Resolution Fault Signature Analysis}

In this section, we describe our power spectrum density estimator based on the MD MUSIC. Then, we derive the maximum likelihood estimator of the amplitudes. Finally, we describe the proposed criterion for fault detection. In the following, for the sake of simplicity, let us note $\mathbf{A}=\mathbf{A}\left(f_{c}, n\right)$ and $\mathbf{D}=\mathbf{D}\left(f_{s}, n\right)$

\section{A. MD MUSIC-Based Frequency Estimation}

Based on the assumption $\mathcal{H}_{2}$, the covariance matrix is given by

$$
\mathbf{R}=E\left\{\mathbf{x}[n] \mathbf{x}^{H}[n]\right\}=E\left\{(\mathbf{D A s}+\mathbf{b}[n]) \times(\mathbf{D A} \mathbf{s}+\mathbf{b}[n])^{H}\right\}=(\mathbf{D A}) \mathbf{P}(\mathbf{D A})^{H}+\sigma^{2} \mathbf{I}_{M}
$$

where $(.)^{H}$ refers to Hermitian matrix transpose, $\mathbf{I}_{M}$ is the $M \times M$ identity matrix and

$$
\mathbf{P}=E\left\{\mathbf{s s}^{H}\right\}
$$

The covariance matrix eigenvalues decomposition can be written as follows

$$
\mathbf{R}=\mathbf{U} \Lambda \mathbf{U}^{H}
$$

where $\Lambda$ is a diagonal matrix containing the eigenvalues $\lambda_{1} \geq \cdots \geq \lambda_{M}$ of $\mathbf{R}$ and $\mathbf{U}$ is a unitary matrix containing the associated eigenvectors. Under the assumption $\mathcal{H}_{1}$ and the fact that $\mathbf{P}$ is non-singular, the 
diagonal matrix $\Lambda$ can be decomposed as

$$
\Lambda=\left[\begin{array}{cc}
\boldsymbol{\lambda} & \mathbf{0} \\
\mathbf{0} & \sigma^{2} \mathbf{I}_{M-2 L-1}
\end{array}\right]
$$

where $\boldsymbol{\lambda}$ is a diagonal matrix containing the $2 \times L+1$ greatest eigenvalues of $\Lambda$. Figure 3 shows an ordered eigenvalues distribution model for a signal composed of $2 L+1$ complex sine waves embedded in a white noise with variance $\sigma^{2}$. Let us decompose $\mathbf{U}$ as follows

$$
\mathbf{U}=[\mathbf{S} \mathbf{G}]
$$

where:

- $\mathbf{S}$ is a $M \times(2 L+1)$ matrix formed from the eigenvectors associated with the $2 \times L+1$ greatest eigenvalues,

- $\mathbf{G}$ is a $M \times(M-2 L-1)$ matrix formed from the eigenvectors associated with the $M-(2 \times L+1)$ least significant ones.

Using (14), it can be shown that:

$$
\mathbf{R G}=(\mathbf{D A}) \mathbf{P}(\mathbf{D A})^{H} \mathbf{G}+\sigma^{2} \mathbf{G}
$$

As $\mathbf{U}$ is a unitary matrix $\left(\mathbf{U}^{H} \mathbf{U}=\mathbf{I}_{M}\right), \mathbf{S}^{H} \mathbf{G}=\mathbf{0}$ and $\mathbf{G}^{H} \mathbf{G}=\mathbf{I}_{M-(2 \times L+1)}$. Then, using (16) and (17), it follows that

$$
\begin{aligned}
\mathbf{R G}=\mathbf{U} \Lambda \mathbf{U}^{H} \mathbf{G}=[\mathbf{S} \mathbf{G}]\left[\begin{array}{cc}
\boldsymbol{\lambda} & \mathbf{0} \\
\mathbf{0} & \sigma^{2} \mathbf{I}_{M-2 L-1}
\end{array}\right]\left[\begin{array}{l}
\mathbf{S}^{H} \\
\mathbf{G}^{H}
\end{array}\right] \mathbf{G} & =[\mathbf{S} \mathbf{G}]\left[\begin{array}{cc}
\boldsymbol{\lambda} & \mathbf{0} \\
\mathbf{0} & \sigma^{2} \mathbf{I}_{M-2 L-1}
\end{array}\right]\left[\begin{array}{c}
\mathbf{0} \\
\mathbf{I}_{M-(2 \times L+1)}
\end{array}\right] \\
& =[\mathbf{S} \mathbf{G}]\left[\begin{array}{c}
\mathbf{0} \\
\sigma^{2} \mathbf{I}_{M-(2 \times L+1)}
\end{array}\right] \\
& =\sigma^{2} \mathbf{G} .
\end{aligned}
$$

Substituting (20c) in (19), we obtain the following result

$$
\text { (DA) } \mathbf{P}(\mathbf{D A})^{H} \mathbf{G}=\mathbf{0}
$$




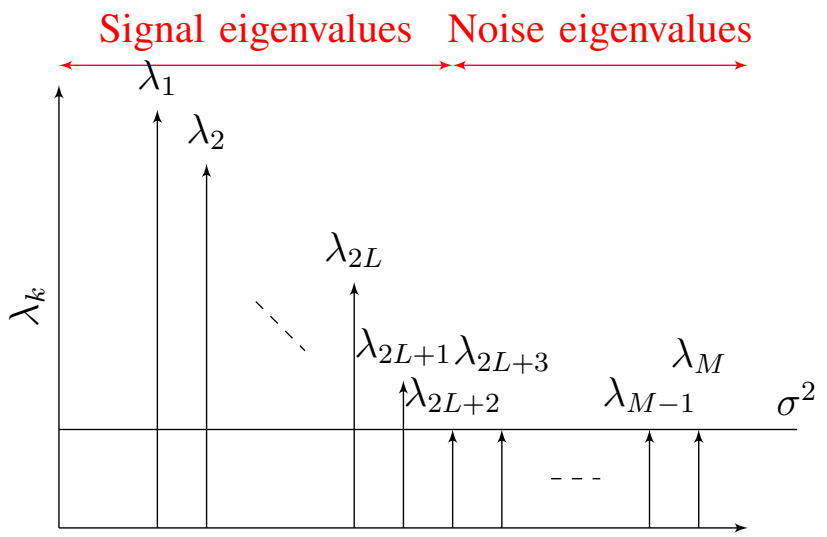

Ordered eigenvalues

Fig. 3. Covariance matrix eigenvalues decomposition [43].

which readily implies

$$
(\mathbf{D A})^{H} \mathbf{G}=\mathbf{0} .
$$

In practice, the samples covariance matrix $\mathbf{R}$ is unknown and should be estimated from the available data. Let

$$
\widehat{\mathbf{R}}=\frac{1}{G} \sum_{n=0}^{G-1} \mathbf{x}[n] \mathbf{x}[n]^{H}
$$

be the estimator of the covariance matrix and $\widehat{\mathbf{U}}=[\widehat{\mathbf{S}} \widehat{\mathbf{G}}]$ be its corresponding eigenvectors. The frequencies $f_{s}$ and $f_{c}$ can then be found as follows

$$
\left\{\widehat{f}_{s}, \widehat{f}_{c}\right\}=\arg \max _{\left\{f_{0}, f_{1}\right\}} \mathcal{J}\left(f_{0}, f_{1}\right)
$$

where

$$
\mathcal{J}\left(f_{0}, f_{1}\right)=\frac{1}{\left\|\left(\mathbf{D}\left(f_{0}\right) \mathbf{A}\left(f_{1}\right)\right)^{H} \widehat{\mathbf{G}}\right\|_{F}^{2}}
$$

and where $\|.\|_{F}^{2}$ denotes the Frobenius norm. If $\widehat{\mathbf{G}}=\mathbf{G},(22)$ and (25) show that the cost-function $\mathcal{J}\left(f_{0}, f_{1}\right)$ tends to infinity for $f_{0}=f_{s}$ and $f_{1}=f_{c}$. In practice, as $\widehat{\mathbf{G}} \approx \mathbf{G}, \mathcal{J}\left(f_{s}, f_{c}\right)$ has a finite value. Figure $1 \mathrm{~b}$ displays the cost-function for a synthetic signal with $f_{s}=50 \mathrm{~Hz}, f_{c}=10 \mathrm{~Hz}, L=2$ and $S N R=50 \mathrm{~dB}$. It can be observed that the cost-function exhibits a well-defined peak at $f_{0}=50 \mathrm{~Hz}$ and $f_{1}=10 \mathrm{~Hz}$. 
The proposed approach requires a priori knowledge about the number of sidebands $L$ for the evaluation of the cost-function. In fact, the estimation of $L$ is of great interest since it allows to improve the frequency estimation (determine the borders between the signal subspace and the noise subspace, which is the most important step on MD MUSIC algorithm). Moreover, the $L$ estimate carries out the information about the fault existence. For $L=0$, the induction machine operate under healthy condition. When $L \neq 0$, a fault occurs and a criterion must be computed in order to determine the fault severity. Finally, It permits to enhance the sensitivity of the fault criterion.

If the number of sidebands is unknown, the cost-function can be modified to take into account the estimation of $L$. Indeed, by following the approach in [52], it can be shown that the fundamental frequency, the fault characteristic frequency, and the number of sidebands $L$ can be estimated by maximizing the following three-dimensional cost-function

$$
\mathcal{J}_{c}\left(f_{0}, f_{1}, L\right)=\frac{(2 L+1) M(M-2 L-1)}{\left\|\left(\mathbf{D}\left(f_{0}\right) \mathbf{A}\left(f_{1}\right)\right)^{H} \widehat{\mathbf{G}}\right\|_{F}^{2}}
$$

For a grid connected induction machine, the supply frequency $f_{s}$ can be assumed to be known. Thus, exploiting this assumption, the cost-function reduces to a two-dimensional one and the optimization problem can be solved using a two-dimensional grid search. For illustration, Fig. 4 displays the proposed cost-function for estimating the number of sidebands $L$, assuming that the fundamental frequency $f_{s}$ is known. The synthetic signal is the same as the one of Fig. $1\left(L=2, f_{c}=10 \mathrm{~Hz}\right)$. The figure shows that the proposed method correctly estimates $L$ and $f_{c}$.

\section{B. MD MUSIC Efficient Implementation}

1) MD MUSIC implementation using FFT: The two major sources of higher computational complexity of the proposed method are the computation of the eigenvalues decomposition (EVD) of the covariance matrix in (23), and the $3-D$ optimization problem in (26). In the following, we will show how the costfunction in (26) can be computed efficiently. Let us define the Fourier matrix $\mathbf{F} \in \mathbb{C}^{F \times F}$, with $F \gg N$, 


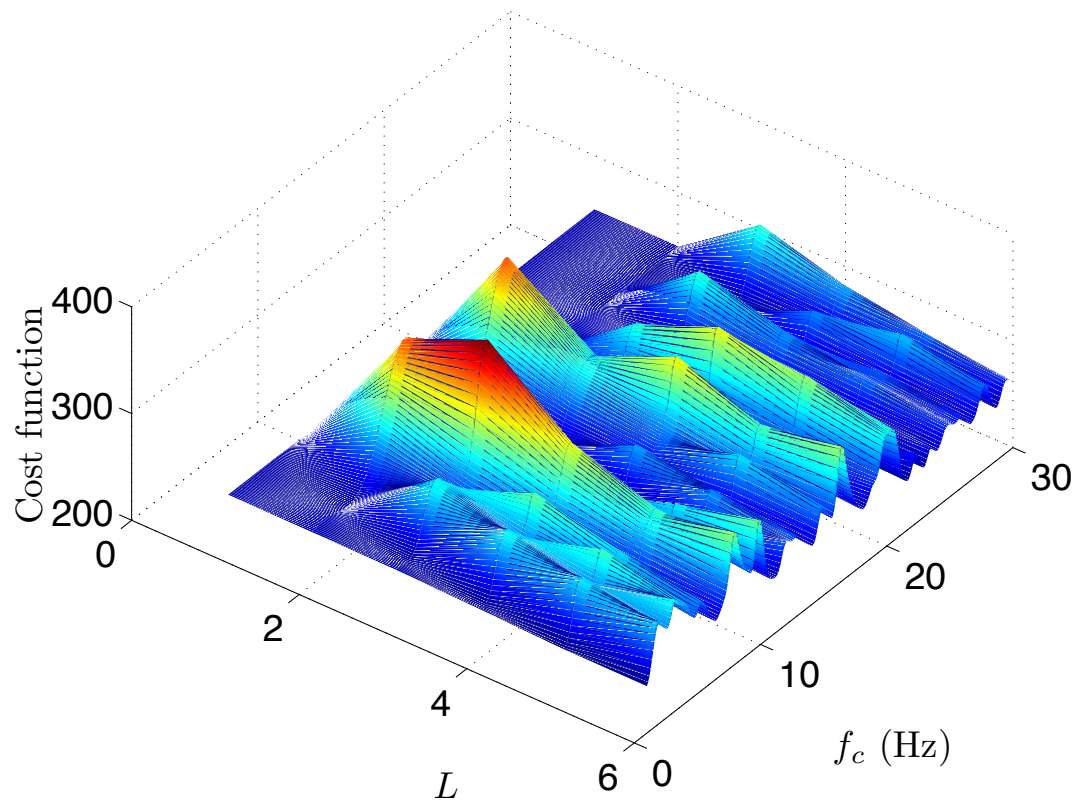

Fig. 4. MD MUSIC cost-function for the estimation of $L$ and $f_{c}$.

as

$$
\mathbf{F}=\left[\begin{array}{ccccc}
1 & 1 & 1 & \ldots & 1 \\
1 & z^{1} & z^{2} & \ldots & z^{(F-1)} \\
\vdots & \vdots & \vdots & \vdots & \\
1 & z^{F-1} & z^{2(F-1)} & \ldots & z^{(F-1)(F-1)}
\end{array}\right]
$$

where $z=e^{-j 2 \pi(1 / F)}$. Next, let us define a matrix $\mathbf{H} \in \mathbb{R}^{F \times M}$ containing the squared absolute values of the inverse FFT of the zero-padded eigenvectors in $\mathbf{U}$ given by (16) as

$$
[\mathbf{H}]_{l m}=\left|\left[\mathbf{F}^{H}\left[\begin{array}{l}
\mathbf{U} \\
0
\end{array}\right]\right]_{l m}\right|^{2}
$$

with $[\mathbf{H}]_{l m}$ being the $(l, m)^{t h}$ element of $\mathbf{H}$. For a candidate of fundamental frequency $2 \pi\left(f_{0} / F\right)$, the fault related frequency $2 \pi\left(f_{1} / F\right)$, and model order $L$, the Frobenius norm can be calculated as follows

$$
\left\|(\mathbf{D A})^{H} \widehat{\mathbf{G}}\right\|_{F}^{2}=\sum_{m=2 \times L+2}^{M} \sum_{l=0}^{2 \times L+1}[\mathbf{H}]_{\left(\left[f_{0} \pm l \times f_{1}\right]+1\right) m}
$$


Thus, the complexity of calculating the cost-function given by (26) for different $f_{s}, f_{c}$, and $L$ can be significantly reduced by calculating the inverse FFT of all eigenvectors once for each given data set. Finally, a sufficiently accurate results at a reasonable computational complexity are obtained using the FFT-based method by maximizing the following cost-function:

$$
\mathcal{J}_{c}\left(f_{0}, f_{1}, L\right)=\frac{(2 L+1) M(M-2 L-1)}{\sum_{m=2 L+2}^{M} \sum_{l=0}^{2 \times L+1}[\mathbf{H}]_{\left(\left[f_{0} \pm l \times f_{1}\right]+1\right) m}}
$$

The relation above gives the relationship between the MUSIC and the Fourier transform, which can be implemented easily using the FFT algorithm. Moreover, this makes the approximate approach attractive since most DSP-boards include functions for FFT computation. This method gives a coarse estimator of the fundamental frequency, fault related frequency, and model order $L$. However, it is more appropriate for faults parameters tracking especially for fast varying parameters. If a very accurate estimates are desired, a refined estimate can be found using the initial cost-function associated with appropriate optimization procedure.

2) Numerical optimization: The maximum of the cost-function in (26) can not be found analytically. Moreover, it is highly multimodal function. Hence, numerical optimization techniques adapted to multimodal functions with various local minima and maxima are required. Since the search space is relatively limited for fundamental frequency $f_{s}$ and $L$, a fixed grid search has been first implemented. This method has the advantage of providing the global maximum in the search space with respect to the chosen grid. However, it is time consuming and requires a fine discretization of the search space to obtain accurate results. Newton-Raphson method is a quite attractive and powerful method. Unfortunately, it requires the computation of the gradient and the Hessian of the cost-function. Moreover, the algorithm can converge to local minima. An efficient class of optimization algorithms are evolutionary algorithms, which include evolutionary programming [53], evolution strategies, and genetic algorithms [54]. The latter outperforms the previously discussed methods in terms of accuracy and computational cost [55]. Consequently, genetic algorithms have been chosen for our application.

\section{MD-MUSIC for non-stationary signals}

The implementation of the MD MUSIC-based technique is based on a batch estimation of eigenvectors of an estimate of signal covariance matrix, making them unsuitable for adaptive processing that is needed 
for non-stationary signal parameters tracking. In fact, the MD MUSIC described earlier is adequate when the stator current are supposed to be stationary. For variable speed drives and transients, the proposed approach can be used for high resolution PSD estimation based on short data acquisition length. In fact, assuming that the signals are stationary for short times, the proposed approach can be used adaptively in order to track the evolution of the fundamental frequency, and the fault related frequency with respect to time. These estimates can be obtained by computing the covariance matrix and the cost-function for consecutive time-frames.

The proposed multidimensional MUSIC relies on the covariance matrix estimation. To do this in a manner that facilitates adaptivity, we may employ the following estimate based on an exponential forgetting factor $0<\lambda<1[56]$ :

$$
\mathbf{R}(n)=(1-\lambda) \mathbf{R}(n-1)+\lambda \mathbf{x}(n) \mathbf{x}^{H}(n)
$$

The forgetting factor controls the trade-off between estimation accuracy and parameters tracking performance of the proposed algorithm. A significant value of the forgetting factor gives less weight to older samples, while a small value gives less weight to newer samples. Once the covariance matrix is estimated, the frequency content and the model order $L$ may be estimated as described in (26).

\section{Maximum Likelihood-Based Amplitude Estimation}

The amplitudes of the frequency components convey the information about the fault severity. These amplitudes are contained in the vector $\mathbf{s}$. The amplitudes and phases can be seen in (9) to be linear complex parameters that can be easily found given the fundamental frequency and the fault related frequency. Note that in practice $f_{c}$ and $f_{s}$ are unknown and must be replaced by their estimates in (32) (see the previous subsection for details). Indeed, maximum likelihood estimator (MLE) of the complex amplitudes $\mathbf{s}$, denoted $\widehat{\mathbf{s}}$, is given by [57]

$$
\widehat{\mathbf{s}}=\left(\sum_{n=0}^{G-1}(\mathbf{D A})^{H}(n)(\mathbf{D A})(n)\right)^{-1} \times \sum_{n=0}^{G-1}(\mathbf{D A})^{H}(n) \mathbf{x}[n]
$$

Let us decompose the $(2 L+1) \times 1$ column vector $\widehat{\mathbf{s}}$ as

$$
\widehat{\mathbf{s}}=\left[\widehat{s}_{-L}, \widehat{s}_{-L+1}, \cdots, \widehat{s}_{L-1}, \widehat{s}_{L}\right]^{T}
$$


Using the structure of $\mathbf{s}$ in (11), the amplitudes $a_{k}$ can be estimated by

$$
\widehat{a}_{k}=\left|\widehat{s}_{k}\right|
$$

The MLE of the amplitudes of the complex sinusoids is efficient [57, Theorem 7.5].

\section{E. Fault Detection Criterion}

In order to successfully perform fault detection, a fault criterion is required to measure the machine state and fault severity. Since the information about the fault is carried out by the sidebands amplitude $a_{k}(k \neq 0)$, we propose to compute the sidebands energy to fundamental frequency energy ratio as a fault indicator [58]. This criterion is expressed mathematically as

$$
\mathcal{C}=\sum_{k=-L, k \neq 0}^{L}\left(\frac{\widehat{a}_{k}^{2}}{\widehat{a}_{0}^{2}}\right)
$$

This criterion allows to measure the fault severity. It can be used as an input for a fault decision algorithm to automatically take decision on the operating state and condition of the machine and detecting any abnormal operating conditions.

The proposed fault detection algorithm is summed up in Fig. 5.

\section{NUMERICAL SimULATIONS}

This section presents the simulation results on stator current issued from a coupled electromagnetic circuits approach-based simulation tool [21], [59]. The proposed approach has been used to detect air-gap eccentricity, emulating bearing faults, whose characteristic frequencies match the analytical stator current model presented in (1).

\section{A. Induction machine modeling}

The machine modeling under faulty conditions has been performed based on the coupled electromagnetic circuits method. The detailed description of this model can be found in [60]. All parameters are calculated from the actual geometry and winding layout of the machines rather than from transformed or equivalent variables.

The considered machine in this study is a three-phase squirrel-cage induction motor with four poles, $4 \mathrm{~kW} / 50 \mathrm{~Hz}, 230 / 400 \mathrm{~V}$. The machine has 28 rotor bars and 48 stator slots. The machine remaining 


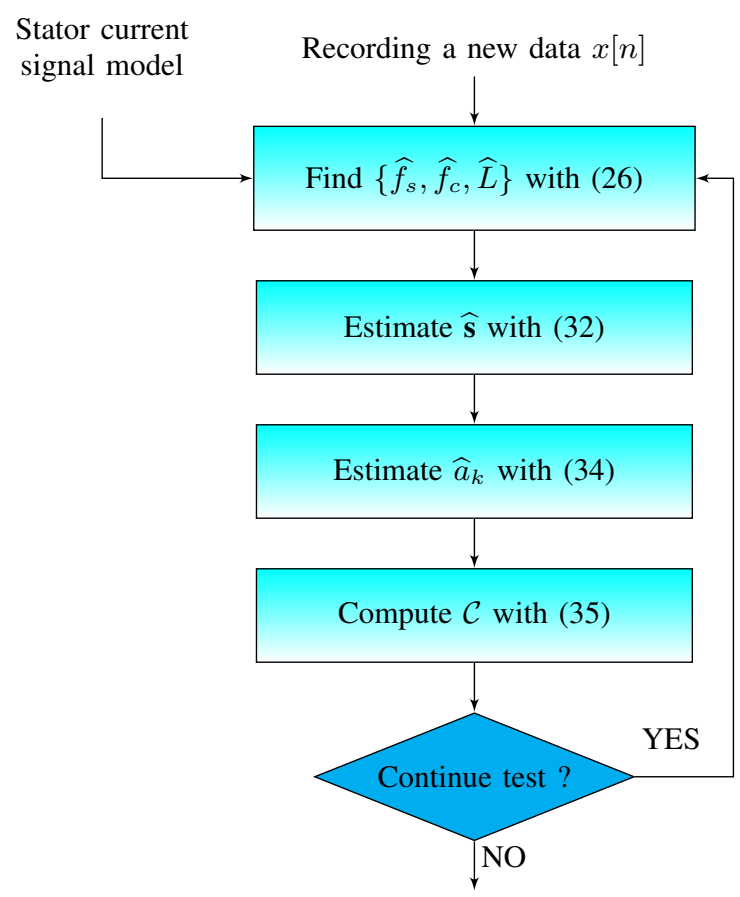

Fault severity/Decision making

Fig. 5. Flowchart of the fault detection algorithm.

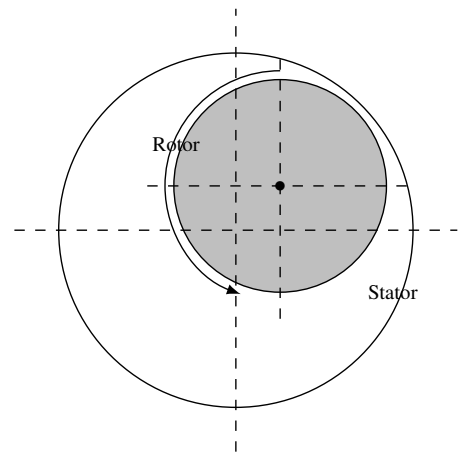

(a) Static eccentricity.

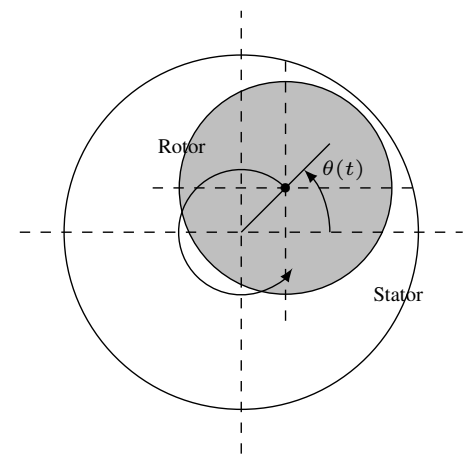

(b) Dynamic eccentricity.

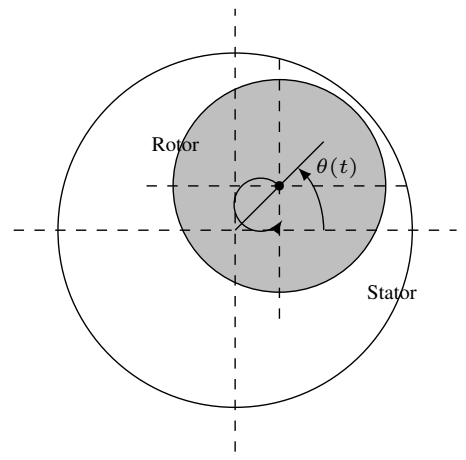

(c) Mixed eccentricity.

Fig. 6. Different types of eccentricity.

parameters are given in Appendix A. It has been demonstrated that single-point bearings faults have an effect over the machine eccentricity and/or load variations [49], [61], [62]. In fact, bearing fault will induce mechanical eccentricities, but also load-torque variations. Hence, in the carried-out simulations, bearing faults are emulated by generating only one sort of physical phenomena: rotating eccentricities at bearing characteristic fault frequency $f_{c}$. These eccentricities lead to periodical changes in the induction machine inductances [49]. Three types of eccentricity are considered; the static, dynamic and mixed eccentricity as illustrated by Fig. 6 . 


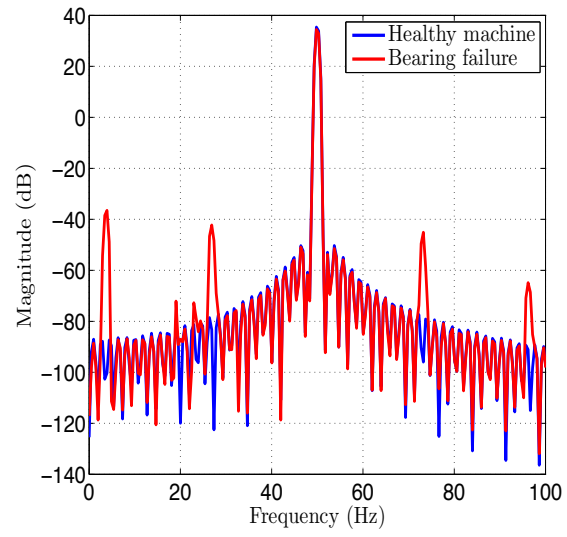

(a) Periodogram (FFT).

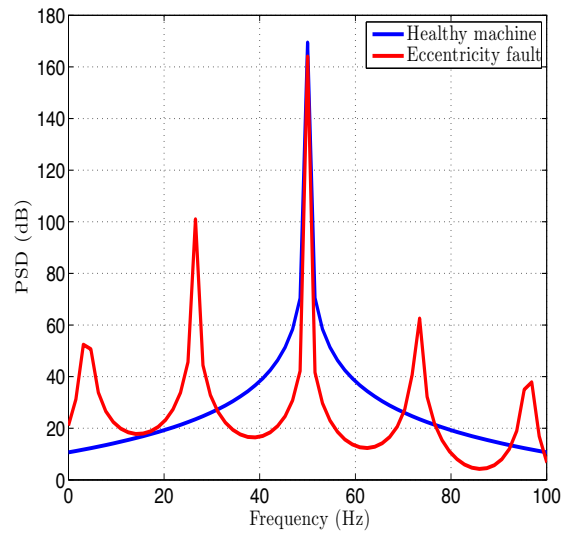

(b) MUSIC (model order equal to 16).

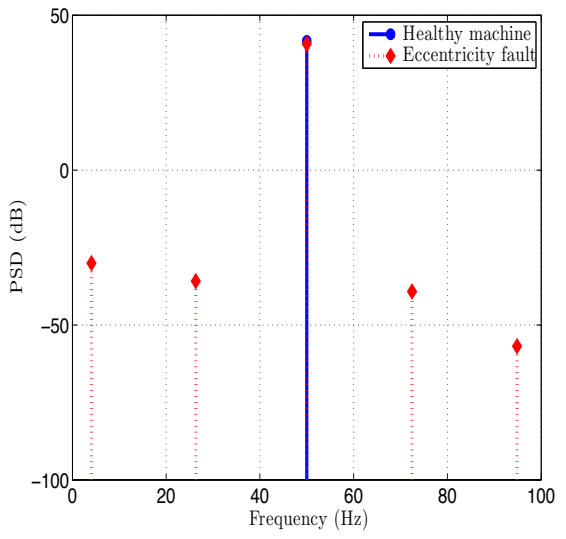

(c) Proposed Approach.

Fig. 7. Stator current PSD for a healthy and a faulty machine (Mixed eccentricity).

The faults have been implemented and stator currents have been retrieved at $2 \mathrm{kHz}$ sampling rate for $2 s$. The stator current PSD for $100 \%$ loaded faulty induction machine with $10 \%$ mixed eccentricity is given by Fig. 7. Figure 7a gives the stator current Periodogram while Figs. 7b and 7c depict the MUSIC and the proposed approach based PSD. These figures show that, for a faulty induction machine, the stator currents model corresponds to the one proposed within this paper. In fact, sidebands appear around the fundamental frequency due to eccentricity fault.

In the following, a single phase stator current has been processed using the proposed MD MUSIC for fault detection. Then, the MLE is used for fault related frequency amplitudes estimation. Finally, the fault criterion $\mathcal{C}$ has been computed in order to measure the fault severity.

\section{B. Emulated Bearing Faults Detection}

Table 1 gives the simulation results for $10 \%$ air-gap eccentricity faults detection based on the proposed approach for a fully loaded induction machine.

These results demonstrate the appropriateness of the proposed approach. In fact, the MD MUSIC allows to distinguish faulty machine from the healthy one by estimating the model order $L$. It is interesting to notice that the proposed approach may be used to distinguish the static eccentricity and the dynamic (mixed) eccentricity based on the model order $L$. In fact, for static eccentricity the model order is equal to 1 , while for dynamic (mixed) this parameter is equal to 2. Moreover, as compared with the classical MUSIC, the proposed approach allows to measure the fault related frequency amplitudes. Once the amplitudes are estimated, the criterion is computed in order to measure the fault severity. This fault detection criterion 
Table 1

MD MUSIC: RESULTS FOR SIMULATED HEALTHY AND FAULTY MACHINE WITH EMULATED BEARING FAULTS.

\begin{tabular}{|c|c|c|c|c|c|}
\hline State & $\begin{array}{c}\widehat{f}_{c} \\
(\mathrm{~Hz})\end{array}$ & $\begin{array}{c}\widehat{f_{s}} \\
(\mathrm{~Hz})\end{array}$ & $\widehat{L}$ & $\begin{array}{l}\widehat{a}_{k} \\
(\mathrm{~A})\end{array}$ & $\begin{array}{c}\mathcal{C} \\
\left(\times 10^{-3}\right)\end{array}$ \\
\hline Healthy & -- & 50 & 0 & $a_{0}=10.5$ & 0 \\
\hline $\begin{array}{l}\text { Static } \\
\text { ecc. }\end{array}$ & 23.15 & 50.001 & 1 & $\begin{array}{c}a_{-1}=0.35 \\
a_{0}=10.11 \\
a_{1}=0.21\end{array}$ & 1.7 \\
\hline $\begin{array}{c}\text { Dynamic } \\
\text { ecc. }\end{array}$ & 23.19 & 50.04 & 2 & $\begin{array}{c}a_{-2}=0.69 \\
a_{-1}=0.075 \\
a_{0}=10.43 \\
a_{1}=0.042 \\
a_{2}=0.002\end{array}$ & 4.5 \\
\hline $\begin{array}{c}\text { Mixed } \\
\text { ecc. }\end{array}$ & 26.14 & 49.98 & 2 & $\begin{array}{c}a_{-2}=0.18 \\
a_{-1}=0.12 \\
a_{0}=10.44 \\
a_{1}=0.1 \\
a_{2}=0.34\end{array}$ & 0.53 \\
\hline
\end{tabular}
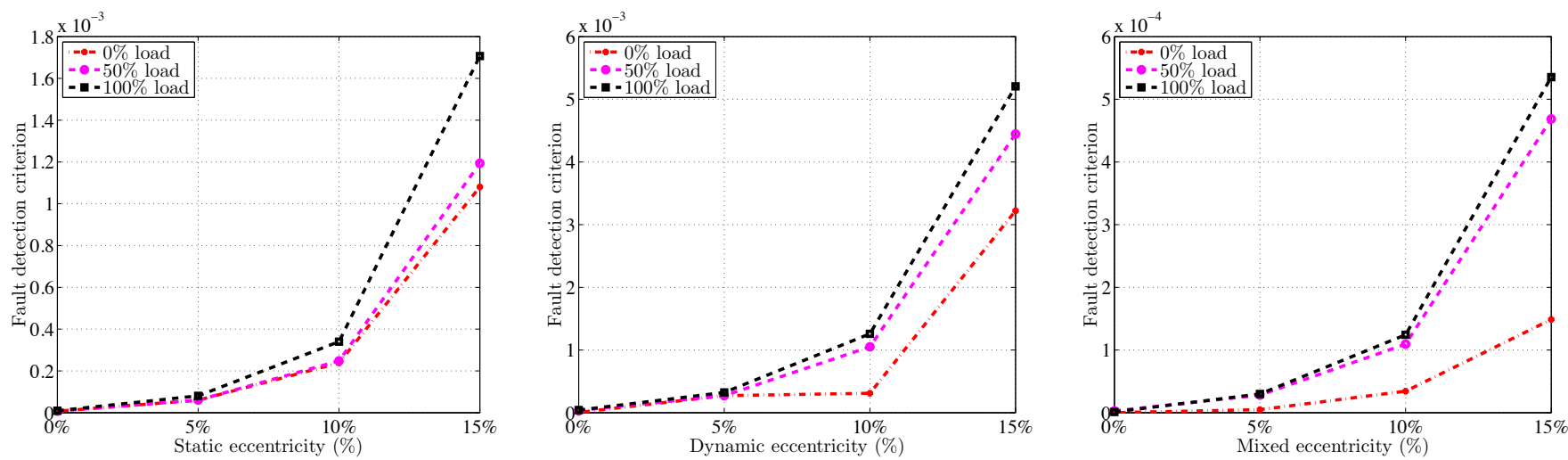

(a) Criterion variation with static eccentricity. (b) Criterion variation with dynamic eccen- (c) Criterion variation with mixed eccentricity.
tricity.

Fig. 8. Eccentricity fault detection-based on the proposed MD MUSIC based approach.

may be used as an input for decision algorithm.

In order to prove the effectiveness of the proposed approach for fault severity tracking, several simulations have been performed with different air-gap eccentricity degrees and for various load conditions. Figure 8 shows the proposed fault detection criterion variation for the static, dynamic, and mixed eccentricities and for different load conditions.

The achieved results clearly show that the proposed approach is able to detect a very low degree of 
eccentricity regardless of the load conditions. Moreover, it can be seen that the fault severity increases when load increases even though the eccentricity degree remains the same.

\section{EXPERIMENTAL RESULTS}

This section reports on the performance of the proposed approach for bearing faults detection in induction machine. The experimental setup is described first, then the proposed approach is applied off-line in Matlab ${ }^{\circledR}$ for different bearing faults severity.

\section{A. Experimental Setup Description}

A conventional $0.75 \mathrm{~kW}$ induction machine drive test rig is used in order to test the proposed fault detection and diagnosis approach. The test rig scheme is given by Fig. 9 and the rated data of the used induction machine are given in Appendix B.

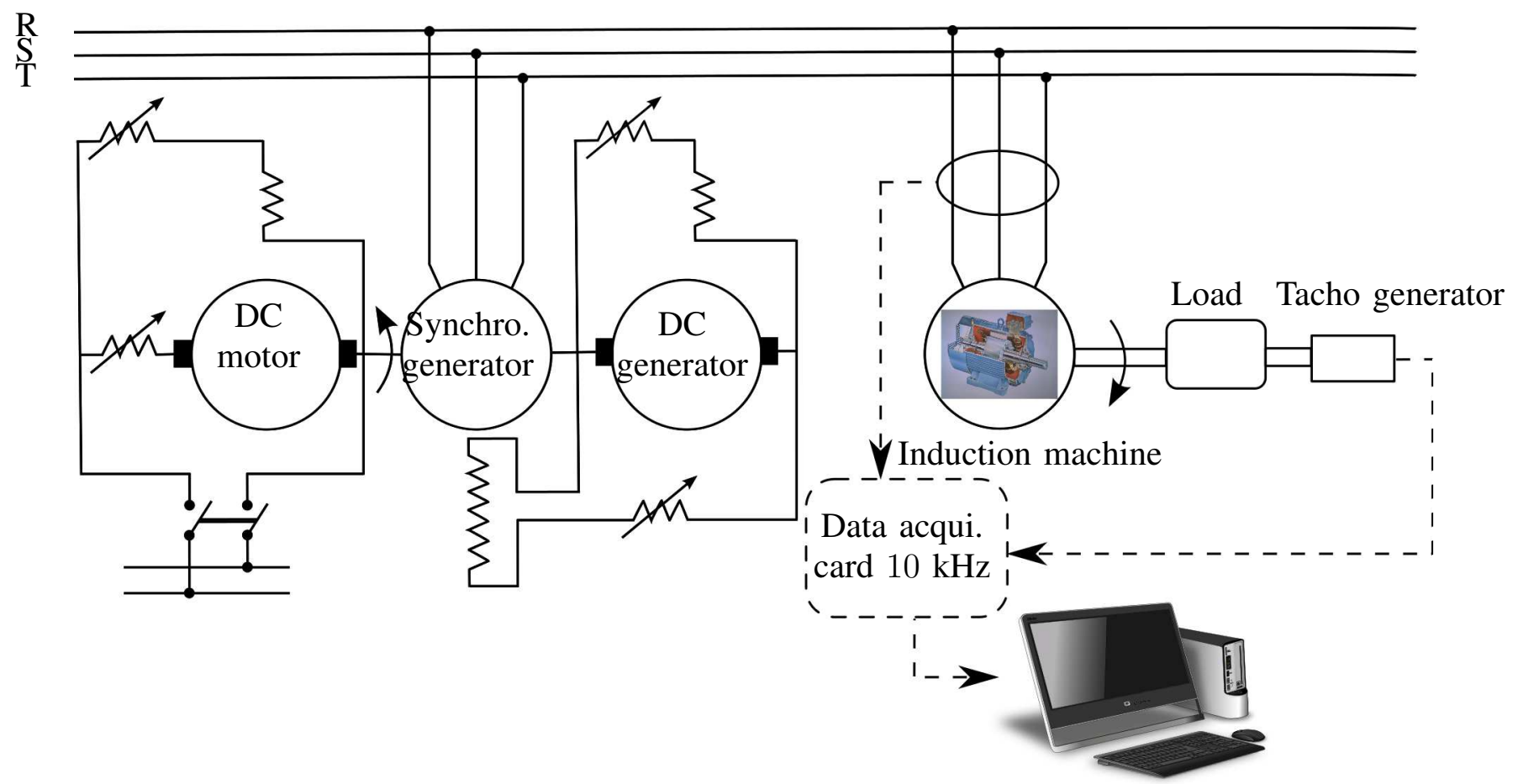

Fault detection algorithm

Fig. 9. Test rig scheme.

The test rig mechanical part is composed by a synchronous and an induction machine. The induction machine is fed by the synchronous generator in order to eliminate time-harmonics. In fact, when fed by a PWM inverter, the induction motor is subjected to voltage harmonics. Depending on the type of the used PWM, the switching frequency and the control strategy, the motor currents contain several 


\begin{tabular}{|c|c|c|c|c|}
\hline $\begin{array}{c}\text { PSD estimation } \\
\text { approach }\end{array}$ & Periodogram & MUSIC & Proposed approach & $\begin{array}{c}\text { Proposed approach } \\
\text { (using FFT) }\end{array}$ \\
\hline CPU time & $0.062 \mathrm{sec}$ & $0.22 \mathrm{sec}$ & $9.89 \mathrm{sec}$ & $1.02 \mathrm{sec}$ \\
\hline
\end{tabular}

COMPUTATIONAL COST OF FFT, MUSIC AND THE PROPOSED APPROACH.

time-harmonics. These time-harmonics can complicate the fault detection process. Moreover, inverters can generate potentially damaging bearing currents. This way, the currents flowing through the induction motor windings are considered near-sinusoidal currents. Indeed, this will automatically eliminate supply harmonics and therefore allow focusing only on bearing faults effect on the stator current. The induction machine has two 6204.2 ZR type bearings (single row and deep groove ball bearings). Bearing faults are obtained by simply drilling holes in different parts.

The measured quantities for off-line bearing fault detection were the line-currents. For all the experiments, the stator fundamental frequency was equal to $f_{s}=50 \mathrm{~Hz}$. All the signals were acquired at a $1 \mathrm{kHz}$ sampling frequency for 20 s by a data acquisition card and processed using Matlab ${ }^{\circledR}$. As the information relative to the bearing faults is mostly contained in the low frequency band, these signals were downsampled at $200 \mathrm{~Hz}$ sampling rate. The stator current waveform and the corresponding PSD based on the Periodogram, the MUSIC and the proposed approach are given by Fig. 10. It can be observed from Fig. 10a that the frequency components related to the fault are present even in the case of a healthy machine. However, their amplitudes increase in the presence of bearing fault. The proposed approach (Fig. 10c) allows to discriminate the frequency components related to the fault and those, which may be related to manufacturing problems or shaft misalignment. The latter are considered as belonging to the noise subspace. Concerning the computational complexity, the CPU time requirements (performed on 1 second signal on a HP ProBook PC at $2.2 \mathrm{GHz}$, using Matlab ${ }^{\circledR}$ ) for the PSD evaluation based on the three approaches is given by Table 2. It can be observed that the proposed approach has higher computational cost than MUSIC or FFT. However, unlike FFT or MUSIC, the proposed approach allows to directly measure a fault indicator while FFT or MUSIC give the signal spectrum. Moreover, the bearing degradation does not evolve rapidly, which make the fault diagnosis based on the proposed technique interesting. It must be emphasized that the proposed approach computational cost depends on the method used to compute the covariance matrix, its eigenvalues and the optimization technique (grid search, gradient, Newton, etc.) used in order to resolve the 3-D optimization problem. Furthermore, as discussed in 3.2.1 the proposed approach can be implemented based on FFT in order to drastically decrease the computational cost. 


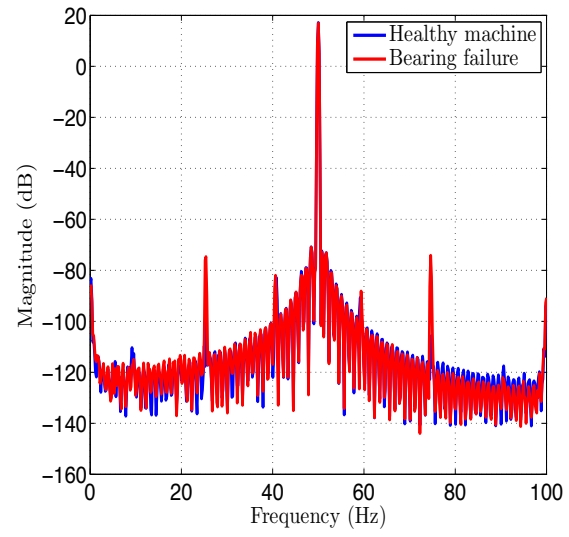

(a) Periodogram-based spectrum (Blackman window).

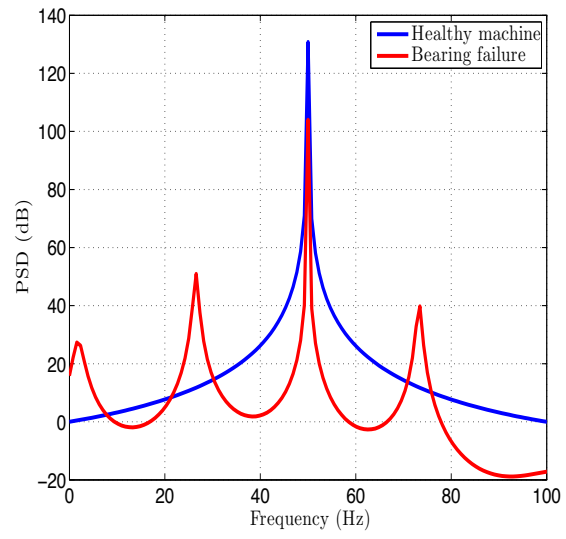

(b) MUSIC-based spectrum.

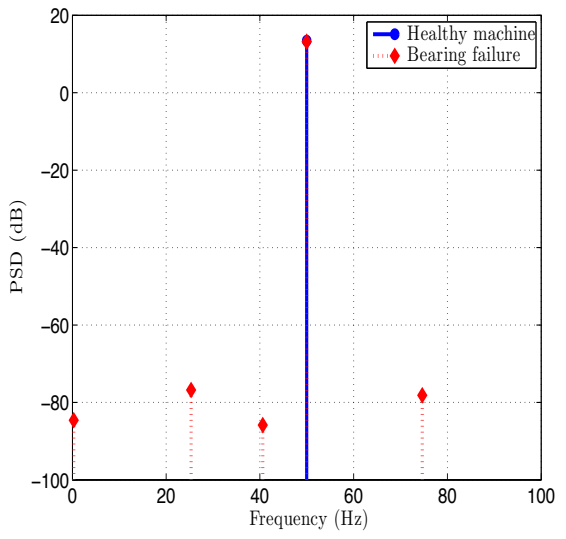

(c) Proposed approach-based spectrum.

Fig. 10. Classical spectrum analysis techniques on experimental data.

Figure 11 gives the stator current waveform in the case of healthy and faulty machine with the corresponding spectrogram. This figure shows that bearing fault can be detected using the stator current since the spectrogram with bearing fault exhibits sidebands around the supply frequency introduced by the fault. Moreover, the sidebands amplitude changes with respect to time. For these reasons, the proposed algorithm is used in order to track the fault severity with respect to time.

The next section describes the appropriateness of the proposed technique for bearing fault detection on the experimental data.

\section{B. Experimental Results Analysis: Artificially Deteriorated Bearings}

The off-line experimental results are summarized on Table 3 for several fault severities. This Table presents the fault criterion variation for healthy and faulty induction machine. The signal length was equal to $1 s$ for these simulations.

This table highlights the presence of the sidebands even if the machine is healthy since the model order is non-zero. A non-zero model order means that the healthy machine presents some asymmetries, which are dues to manufacturing problems [63]. However, these sidebands amplitude is lower than in the faulty case. The criterion computed using these amplitudes increases in the case of faulty machine. Therefore, It can be assumed that the proposed fault criterion, which is based on MD MUSIC and MLE for the amplitude, gives a reliable fault indicator.

In order to investigate the criterion variations with respect to time, experiments have been performed for 20 seconds. The proposed approach was then applied on signal sub-vectors in order to demonstrate 


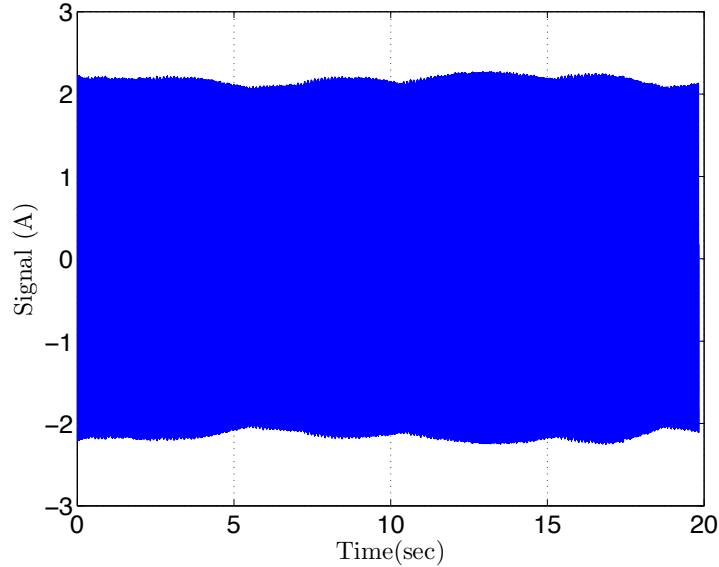

(a) Stator current waveform in healthy case.

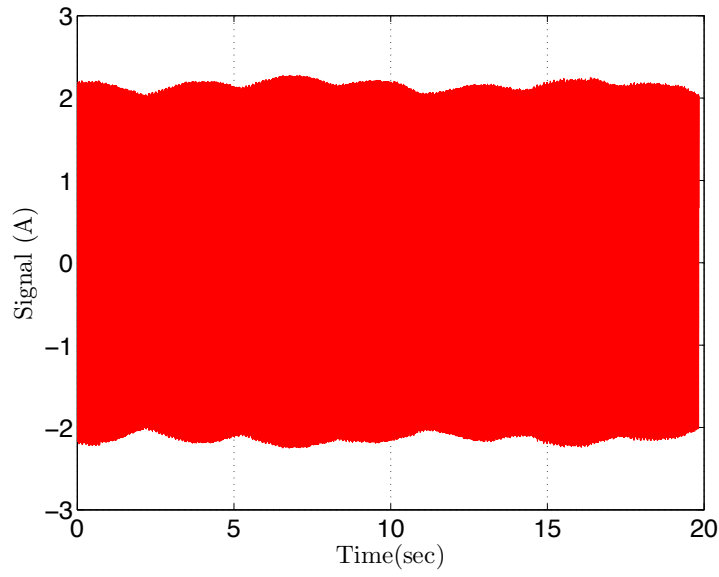

(c) Stator current waveform with bearing fault.

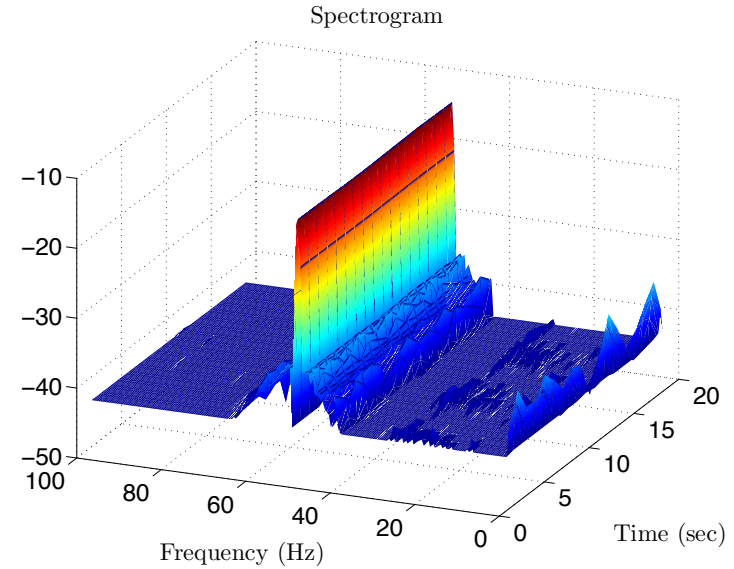

(b) Stator current spectrogram in healthy case.

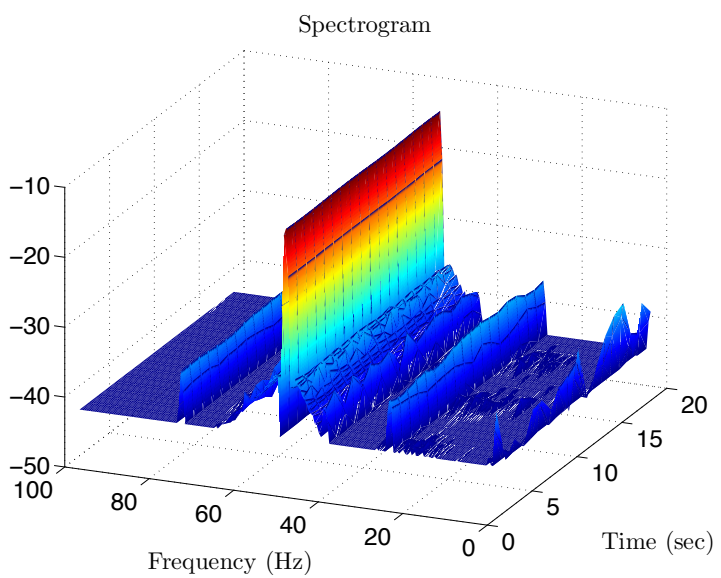

(d) Stator current spectrogram with bearing fault.

Fig. 11. Experimental data analysis.

the usefulness of the proposed approach for fault tracking. Figure 12 summarizes the experimental results for several fault severities.

From this figure, it can be concluded that the proposed fault detection criterion is sensitive to the fault but varies with respect to time. However, It remains higher in the case of a faulty machine compared to the healthy one.

\section{CONCLUSION}

This paper have proposed a new induction machine faults detection scheme using the stator current. Indeed, MD MUSIC associated with MLE has been proposed and demonstrated for bearing faults detection in induction machines. The model order estimation (sidebands number produced by the fault and there localization) enhances the fault indicator reliability and then allows to detect incipient faults. This method could be adapted to any kind of fault assuming that the fault characteristic frequencies are known. 
Table 3

MD MUSIC: RESULTS FOR EXPERIMENTAL HEALTHY AND FAULTY MACHINES WITH $L$ ESTIMATION FOR BEARING FAULTS DETECTION.

\begin{tabular}{|c|c|c|c|c|c|}
\hline State & $\begin{array}{c}\widehat{f_{s}} \\
(\mathrm{~Hz})\end{array}$ & $\begin{array}{c}\widehat{f_{c}} \\
(\mathrm{~Hz})\end{array}$ & $\widehat{L}$ & $\begin{array}{l}\widehat{a}_{k} \\
(\mathrm{~A})\end{array}$ & $\begin{array}{c}\mathcal{C} \\
\left(\times 10^{-5}\right)\end{array}$ \\
\hline $\begin{array}{l}\text { Healthy } \\
\text { machine }\end{array}$ & 49.92 & 8.4020 & 2 & $\begin{aligned} a_{-2} & =0.0014 \\
a_{-1} & =0.0012 \\
a_{0} & =2.1648 \\
a_{1} & =0.0016 \\
a_{2} & =0.0032\end{aligned}$ & 0.33736 \\
\hline $\begin{array}{c}\text { Bearing } \\
\text { fault } \\
\text { (severity 1) }\end{array}$ & 49.99 & 24.918 & 1 & $\begin{array}{c}a_{-1}=0.0081 \\
a_{0}=2.1371 \\
a_{1}=0.006\end{array}$ & 2.2116 \\
\hline $\begin{array}{c}\text { Bearing } \\
\text { fault } \\
\text { (severity 2) }\end{array}$ & 50.07 & 24.8294 & 2 & $\begin{aligned} a_{-2} & =0.0066 \\
a_{-1} & =0.0105 \\
a_{0} & =1.9856 \\
a_{1} & =0.0069 \\
a_{2} & =0.0039\end{aligned}$ & 5.5043 \\
\hline $\begin{array}{c}\text { Bearing } \\
\text { fault } \\
\text { (severity 3) }\end{array}$ & 50.05 & 24.8401 & 2 & $\begin{aligned} a_{-2} & =0.0094 \\
a_{-1} & =0.0110 \\
a_{0} & =2.0837 \\
a_{1} & =0.0079 \\
a_{2} & =0.0058\end{aligned}$ & 7.037 \\
\hline
\end{tabular}

The proposed bearing fault detection was first tested using stator currents issued from coupled electromagnetic circuits approach based tool. Then, an experimental validation was performed on induction machine with bearing faults. The carried-out simulations and experiments obviously confirm the appropriateness of the stator current model and the proposed MD MUSIC-MLE fault detection approach.

The advantages of this noninvasive approach compared to other existing methods are its ability to extract information about the fault existence and then to compute criterion allowing to measure its severity. Moreover, the frequency components introduced by the fault depend on the machine operating conditions. Consequently, the proposed approach allows to directly estimate the fault characteristic frequency without estimating the machine speed or slip.

Further investigations are required in order to validate the proposed approach on generalized roughness, which is the most common damage occurring on rolling bearings. Additional works will be performed in order to propose an appropriate optimization algorithm that may contribute to decrease the computational 


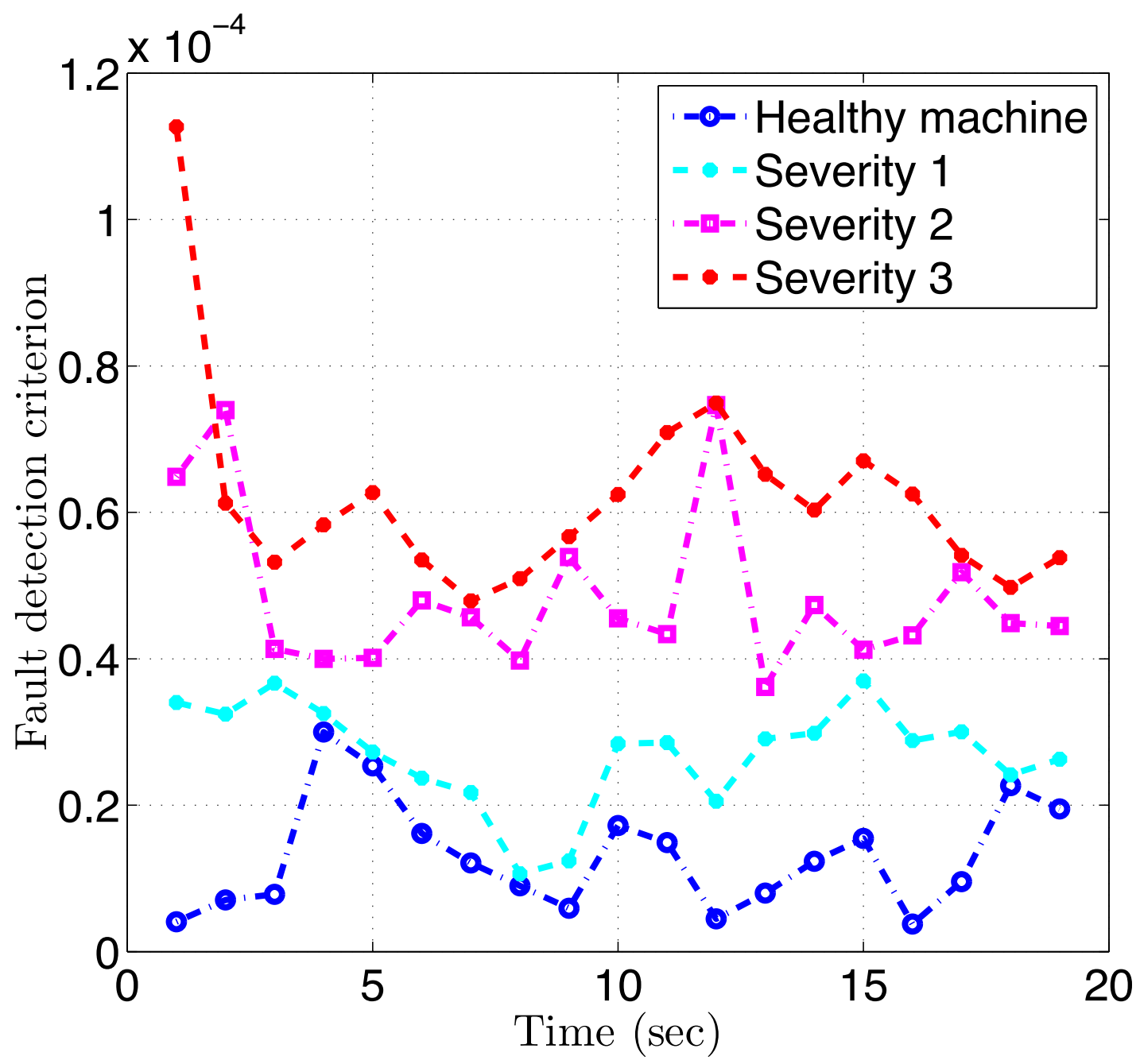

Fig. 12. Criterion variations for bearing fault detection using the proposed MD MUSIC-based approach.

cost. Moreover, the proposed approach will be validated for variable frequency power supply and adjustable speed drives.

\section{REFERENCES}

[1] P. Zhang, Y. Du, T. Habetler, and B. Lu, "A survey of condition monitoring and protection methods for medium-voltage induction motors," IEEE Transactions on Industry Applications, vol. 47, no. 1, pp. 34-46, Jan./Feb. 2011.

[2] A. H. Bonnett and C. Yung, "Increased efficiency versus increased reliability," IEEE Industry Applications Magazine, vol. 14, no. 1, 2008.

[3] S. Cheng, Y. Du, J. A. Restrepo, P. Zhang, and T. G. Habetler, "A nonintrusive thermal monitoring method for induction motors fed by closed-loop inverter drives," IEEE Transactions on Power Electronics, vol. 27, no. 9, pp. 4122-4131, Sept. 2012.

[4] A. Bellini, F. Filippetti, C. Tassoni, and G. A. Capolino, “Advances in Diagnostic Techniques for Induction Machines," IEEE Transactions on Industrial Electronics, vol. 55, no. 12, pp. 4109-4126, Dec. 2008.

[5] M. E. H. Benbouzid, "A review of induction motors signature analysis as a medium for faults detection," IEEE Transactions on Industrial Electronics, vol. 47, no. 5, pp. 984-993, Oct. 2000. 
[6] J. Seshadrinath, B. Ketan Panigrahi et al., "Investigation of vibration signatures for multiple fault diagnosis in variable frequency drives using complex wavelets," IEEE Transactions on Power Electronics, vol. 29, no. 2, pp. 936-945, Feb. 2014.

[7] P. Henríquez Rodríguez, J. B. Alonso, M. A. Ferrer, and C. M. Travieso, "Application of the teager-kaiser energy operator in bearing fault diagnosis," ISA transactions, vol. 52, no. 2, pp. 278-284, 2013.

[8] L. Guo, J. Chen, and X. Li, "Rolling bearing fault classification based on enveloppe spectrum and support vector machine," Journal of Vibration and Control, vol. 15, no. 9, pp. 1349-1363, Jul. 2009.

[9] D. G. Dorrell, W. T. Thomson, and S. Roach, "Analysis of airgap flux, current, and vibration signals as a function of the combination of static and dynamic airgap eccentricity in 3-phase induction motors," IEEE Transactions on Industry Applications, vol. 33, no. 1, pp. 24-34, Jan./Fer. 1997.

[10] C. Chakraborty and V. Verma, "Speed and current sensor fault detection and isolation technique for induction motor drive using axes transformation," Industrial Electronics, IEEE Transactions on, vol. 62, no. 3, pp. 1943-1954, 2015.

[11] M. Salah, K. Bacha, and A. Chaari, "Comparative investigation of diagnosis media for induction machine mechanical unbalance fault," ISA transactions, vol. 52, no. 6, pp. 888-899, 2013.

[12] I. P. Georgakopoulos, E. D. Mitronikas, and A. N. Safacas, "Detection of induction motor faults in inverter drives using inverter input current analysis," Industrial Electronics, IEEE Transactions on, vol. 58, no. 9, pp. 4365-4373, 2011.

[13] V. C. Leite, B. da Silva, J. Guedes, G. F. Cintra Veloso, L. E. Borges da Silva, G. Lambert-Torres, E. L. Bonaldi, and L. E. De Lacerda de Oliveira, "Detection of localized bearing faults in induction machines by spectral kurtosis and envelope analysis of stator current," Industrial Electronics, IEEE Transactions on, vol. 62, no. 3, pp. 1855-1865, 2015.

[14] H. Torkaman and E. Afjei, "Comprehensive detection of eccentricity fault in switched reluctance machines using high-frequency pulse injection," IEEE Transactions on Power Electronics, vol. 28, no. 3, pp. 1382-1390, March 2013.

[15] V. Choqueuse, M. E. H. Benbouzid, Y. Amirat, and S. Turri, "Diagnosis of three-phase electrical machines using multidimensional demodulation techniques," IEEE Transactions on Industrial Electronics, vol. 59, no. 4, pp. 2014-2023, April 2012.

[16] R. Sharifi and M. Ebrahimi, "Detection of stator winding faults in induction motors using three-phase current monitoring," ISA transactions, vol. 50, no. 1, pp. 14-20, 2011.

[17] M. Blodt, J. Regnier, and J. Faucher, "Distinguishing load torque oscillations and eccentricity faults in induction motors using stator current wigner distributions," IEEE Transactions on Industry Applications, vol. 45, no. 6, pp. 1991-2000, Nov./Dec. 2009.

[18] S. Kia, H. Henao, and G. Capolino, "Analytical and experimental study of gearbox mechanical effect on the induction machine stator current signature," IEEE Transactions on Industry Applications, vol. 45, no. 4, pp. 1405-1415, Jul./Aug. 2009.

[19] R. L. de Araujo Ribeiro, C. B. Jacobina, E. Cabral da Silva, and A. N. Lima, "Fault detection of open-switch damage in voltage-fed pwm motor drive systems," IEEE Transactions on Power Electronics, vol. 18, no. 2, pp. 587-593, March 2003.

[20] S. Ben Salem, K. Bacha, and A. Chaari, "Support vector machine based decision for mechanical fault condition monitoring in induction motor using an advanced hilbert-park transform," ISA transactions, vol. 51, no. 5, pp. 566-572, 2012.

[21] A. Ceban, R. Pusca, and R. Romary, "Study of rotor faults in induction motors using external magnetic field analysis," IEEE Transactions on Industrial Electronics, vol. 59, no. 5, pp. 2082-2096, May 2012.

[22] E. Elbouchikhi, V. Choqueuse, and M. Benbouzid, "Induction machine diagnosis using stator current advanced signal processing," International Journal on Energy Conversion, vol. 3, no. 3, pp. 1-12, May 2015.

[23] M. E. H. Benbouzid and G. B. Kliman, "What stator current processing based technique to use for induction motor rotor faults diagnosis?" IEEE Transactions on Energy Conversion, vol. 18, no. 2, pp. 238-244, June 2003.

[24] Y.-H. Kim, Y.-W. Youn, D.-H. Hwang, J.-H. Sun, and D.-S. Kang, "High-resolution parameter estimation method to identify broken rotor bar faults in induction motors," IEEE Transactions on Industrial Electronics, vol. 60, no. 9, pp. 4103-4117, September 2013. 
[25] B. Xu, L. Sun, L. Xu, and G. Xu, "Improvement of the hilbert method via esprit for detecting rotor fault in induction motors at low slip,” IEEE transactions on Energy Conversion, vol. 28, no. 1, pp. 225-233, March 2013.

[26] A. Garcia-Perez, R. de Jesus Romero-Troncoso, E. Cabal-Yepez, and R. Osornio-Rios, "The application of high-resolution spectral analysis for identifying multiple combined faults in induction motors," IEEE Transactions on Industrial Electronics, vol. 58, no. 5, pp. 2002-2010, May 2011.

[27] A. Bracale, G. Carpinelli, L. Piegari, and P. Tricoli, "A high resolution method for on line diagnosis of induction motors faults," in Proceedings of the 2007 IEEE PowerTech, Lausanne, Suisse, 2007, pp. 994-998.

[28] S. H. Kia, H. Henao, and G. Capolino, "A high-resolution frequency estimation method for three-phase induction machine fault detection," IEEE Trans. on Industrial Electronics, vol. 54, no. 4, pp. 2305-2314, Aug. 2007.

[29] M. E. H. Benbouzid, M. Vieira, and C. Theys, "Induction motors faults detection and localization using stator current advanced signal processing techniques," IEEE Transactions on Power Electronics, vol. 14, no. 1, pp. 14-22, Jan. 1999.

[30] E. Elbouchikhi, V. Choqueuse, and M. Benbouzid, "Induction machine faults detection using stator current parametric spectral estimation," Mechanical Systems and Signal Processing, vol. 52, no. 447-464, 2015.

[31] J. Pons-Llinares, J. Antonino-Daviu, M. Riera-Guasp, S. B. Lee, T.-j. Kang, C. Yang et al., "Advanced induction motor rotor fault diagnosis via continuous and discrete time-frequency tools," Industrial Electronics, IEEE Transactions on, vol. 62, no. 3, pp. 1791-1802, 2015 .

[32] F. Vedreno-Santos, M. Riera-Guasp, H. Henao, M. Pineda-Sanchez, and R. Puche-Panadero, "Diagnosis of rotor and stator asymmetries in wound-rotor induction machines under nonstationary operation through the instantaneous frequency," Industrial Electronics, IEEE Transactions on, vol. 61, no. 9, pp. 4947-4959, 2014.

[33] J. Urresty, J.-R. Riba Ruiz, and L. Romeral, "Diagnosis of interturn faults in pmsms operating under nonstationary conditions by applying order tracking filtering," IEEE Transactions on Power Electronics, vol. 28, no. 1, pp. 507-515, Jan. 2013.

[34] E. Elbouchikhi, V. Choqueuse, M. E. H. Benbouzid, J. Charpentier, and G. Barakat, "A comparative study of time-frequency representations for fault detection in wind turbine," in Proceedings of the 2011 IEEE IECON, Melbourne (Australia), Nov. 2011, pp. 3584-3589.

[35] M. Blodt, M. Chabert, J. Regnier, and J. Faucher, "Mechanical load fault detection in induction motors by stator current time-frequency analysis," IEEE Transactions on Industry Applications, vol. 42, no. 6, pp. 1454-1463, Nov./Dec. 2006.

[36] J.Pons-Llinares, J. Antonino-Daviu, M. Riera-Guasp, M. Pineda-Sanchez, and V. Climente-Alarcon, "Induction motor diagnosis based on a transient current analytic wavelet transform via frequency b-splines," IEEE Transactions Industrial Electronics, vol. 58, no. 5, pp. 1530-1544, May 2011.

[37] A. Bellini, G. Franceschini, and C. Tassoni, "Monitoring of induction machines by maximum covariance method for frequency tracking," IEEE Transactions on Industry Applications, vol. 42, no. 1, pp. 69-78, Jan./Feb. 2006.

[38] B. Yazici and G. B. Kliman, "An adaptive statistical time-frequency method for detection of broken bars and bearing faults in motors using stator current," IEEE Transactions on Industry Applications, vol. 35, no. 2, pp. 442-452, Mar./Apr. 1999.

[39] P. Stoica and Y. Seln, “A review of information criterion rules," IEEE Signal Processing Magazine, vol. 21, no. 4, pp. 36-47, July 2004.

[40] M. Wax and T. Kailath, "Detection of signals by information theoritic criteria," IEEE Transactions on Acoustics, Speech and Signal Processing, vol. ASSP-33, pp. 387-392, Apr. 1985.

[41] M. Viberg and B. Ottersten, "Sensor array processing based on subspace fitting," IEEE Transactions on Signal Processing, vol. 39, no. 5, pp. 1110-1121, May 1991. 
[42] E. Elbouchikhi, V. Choqueuse, M. Benbouzid, and J. F. Charpentier, "Induction machine fault detection enhancement using a stator current high resolution spectrum,” in Proceedings of the 2012 IEEE IECON, Montreal (Canada), October 2012, pp. 3913-3918.

[43] P. Stoica and R. Moses, Introduction to Spectral Analysis. Prentice Hall, 1997.

[44] P. Stoica and A. Nehorai, "Music, maximum likelihood, and cramer-rao bound," IEEE Trans. Acoustics, Speech, and Signal Processing, vol. 37, no. 5, pp. 720-741, May 1989.

[45] F. Immovilli, M. Cocconcelli, A. Bellini, and R. Rubini, "Detection of generalized-roughness bearing fault by spectral-kurtosis energy of vibration or current signals," IEEE Transactions on Industrial Electronics, vol. 56, no. 11, pp. 4710-4717, 2009.

[46] C. M. Riley, B. K. Lin, T. G. Habetler, and G. B. Kliman, "Stator current harmonics and their causal vibrations: a preliminary investigation of sensorless vibration monitoring applications," IEEE Transactions on Industry Applications, vol. 35, no. 1, pp. 94-99, 1999.

[47] M. Blodt, P. Granjon, B. Raison, and G. Rostaing, "Models for bearing damage detection in induction motors using stator current monitoring," IEEE Transactions on Industrial Electronics, vol. 55, no. 4, pp. 1813-1822, April 2008.

[48] B. Li, M.-Y. Chow, Y. Tipsuwan, and J. C. Hung, "Neural-network-based motor rolling bearing fault diagnosis," IEEE Transactions on Industrial Electronics, vol. 47, no. 5, pp. 1060-1069, 2000.

[49] R. Schoen, T. Habetler, F. Kamran, and R. Bartheld, "Motor bearing damage detection using stator current monitoring," IEEE Transactions on Industry Applications, vol. 31, no. 5, pp. 1274-1279, Nov./Dec. 1995.

[50] A. Papoulis and S. U. Pillai, Probability, random variables, and stochastic processes. Tata McGraw-Hill Education, 2002.

[51] M. Rosenblatt, "A central limit theorem and a strong mixing condition," Proceedings of the National Academy of Sciences of the United States of America, vol. 42, no. 1, p. 43, 1956.

[52] M. G. Christensen, A. Jakobsson, and S. H. Jensen, "Joint high-resolution fundamental frequency and order estimation," IEEE Transactions Audio, Speech, and Language Processing, vol. 15, no. 5, pp. 1635-1644, July 2007.

[53] T. Bäck, Evolutionary algorithms in theory and practice. Oxford University Press, New York, 1996.

[54] M. Gen and R. Cheng, Genetic algorithms and engineering optimization. Wiley-interscience, 1999, vol. 7.

[55] S. C. Chapra and R. P. Canale, Numerical methods for engineers. McGraw-Hill, 2012, vol. 2.

[56] J.-F. Yang and M. Kaveh, "Adaptive eigensubspace algorithms for direction or frequency estimation and tracking," IEEE Transactions on Acoustics, Speech and Signal Processing, vol. 36, no. 2, pp. 241-251, 1988.

[57] S. Kay, Fundamentals of Statistical Signal Processing: Estimation Theory. Prentice-Hall signal processing series, 1993, 17th Printing.

[58] G. Bouleux, "Oblique projection pre-processing and tls application for diagnosing rotor bar defects by improving power spectrum estimation,” Mechanical Systems and Signal Processing, vol. 41, no. 1, pp. 301-312, Dec. 2013.

[59] E. Elbouchikhi, V. Choqueuse, and M. E. H. Benbouzid, "Current frequency spectral subtraction and its contribution to induction machines' bearings condition monitoring," IEEE Transactions on Energy Conversion, vol. 28, no. 1, pp. 135-144, March 2013.

[60] H. Toliyat and T. Lipo, "Transient analysis of cage induction machines under stator, rotor bar and end ring faults," IEEE Transactions on Energy Conversion, vol. 10, no. 2, pp. 241-247, 1995.

[61] M. Blödt, P. Granjon, B. Raison, J. Regnier et al., "Mechanical fault detection in induction motor drives through stator current monitoring-theory and application examples," Fault Detection, Wei Zhang (Ed.), pp. 451-488, 2010.

[62] A. Knight and S. Bertani, "Mechanical fault detection in a medium-sized induction motor using stator current monitoring," IEEE Transactions Energy Conversion, vol. 29, no. 4, pp. 753-760, December 2005.

[63] J. Faiz, B. M. Ebrahimi, B. Akin, and H. A. Toliyat, "Finite-element transient analysis of induction motors under mixed eccentricity fault," IEEE Transactions on Magnetics, vol. 44, no. 1, pp. 66-74, Jan. 2008. 


\section{APPENDIX A}

Table 4

Rated Data of the Simulated Induction Machine.

\begin{tabular}{|c||c|c|}
\hline Symbol & Quantity & Machine \\
\hline$P_{n}$ & nominal power & $4 \mathrm{~kW}$ \\
\hline$f_{s}$ & supply frequency & $50 \mathrm{~Hz}$ \\
\hline$V_{n}$ & supply voltage & $230 / 400 \mathrm{~V}$ \\
\hline$I_{n}$ & nominal current & $9.1 \mathrm{~A}$ \\
\hline$\Omega_{n}$ & nominal speed & $1425 \mathrm{rpm}$ \\
\hline$p$ & number of pole pairs & 2 \\
\hline$q$ & number of rotor bars & 28 \\
\hline$N_{s}$ & number of stator slots & 48 \\
\hline$J$ & inertia & $0.0131 \mathrm{~kg} \cdot \mathrm{m}^{2}$ \\
\hline$R_{s}$ & stator phase resistance & $1.5 \Omega$ \\
\hline$R_{b}$ & bar resistance & $69.9 \cdot 10^{-6} \Omega$ \\
\hline$R_{e}$ & end ring resistance & $5 \cdot 10^{-6} \Omega$ \\
\hline$L_{b}$ & rotor bar leakage inductance & $0.28 \cdot 10^{-6} \mathrm{H}$ \\
\hline$L_{e}$ & end ring leakage inductance & $0.036 \cdot 10^{-6} \mathrm{H}$ \\
\hline$L$ & length of the magnetic circuit & $148 \cdot 10^{-3} \mathrm{~m}$ \\
\hline$R_{a v}$ & average radius of the air-gap & $45 \cdot 10^{-3} \mathrm{~m}$ \\
\hline$e$ & air-gap thickness & $0.28 \cdot 10^{-3} \mathrm{~m}$ \\
\hline
\end{tabular}

\section{APPENDIX B}

Table 5

Rated Data of the Tested Induction Machine.

\begin{tabular}{|c||c|}
\hline Quantity & Machine \\
\hline nominal power & $0.75 \mathrm{~kW}$ \\
\hline supply frequency & $50 \mathrm{~Hz}$ \\
\hline supply voltage & $220 / 380 \mathrm{~V}$ \\
\hline nominal current & $3.4 / 1.95 \mathrm{~A}$ \\
\hline nominal speed & $2780 \mathrm{rpm}$ \\
\hline number of pole pairs & $p=1$ \\
\hline
\end{tabular}

